\title{
Academic Research Perspective of LEDs for the Horticulture Industry
}

\author{
Cary A. Mitchell ${ }^{1,2}$ \\ Department of Horticulture \& Landscape Architecture, Purdue University, 625 Agriculture Mall Drive, \\ West Lafayette, IN 47907-2010
}

Additional index words. academia, industry, light-emitting diodes, specialty crops, technology

\begin{abstract}
Following is the invited perspective of an academic researcher and director of a multi-institutional research and education project tasked to test the feasibility of adopting light-emitting diode (LED) technology for application by the commercial horticulture industry. Academics researching basic specialty-crop responses to spectra, intensities, and durations of lighting with LEDs often find technical queries from growers, vendors, and entrepreneurs to go beyond the capabilities and scope of systematic research to answer definitively. Differences between commercial and academic research approaches to LED technology development are noted, including legal obstacles to open collaboration. Early generation commercial LED technology for horticultural applications is based on research begun $>20$ years ago. The basis for selection of various LED wavebands for inclusion in LED plant growth arrays is presented for both commercial as well as research applications. Advantages of light distribution from LED sources for different crop applications are presented, especially including close-canopy and intracanopy lighting, both of which contribute substantially to energy savings. Challenges to providing accurate LED light prescriptions for different crops are discussed, including those for supplemental lighting as well as for sole-source lighting applications. Anticipated trends are projected for horticultural applications of LED technology, including multispectral, individually adjustable, high-intensity arrays; increasing electrical efficacy of future LEDs; and reduced costs of mass production for particular applications.
\end{abstract}

The author is Project Director of a multiinstitutional research and education project involving The University of Arizona, Michigan State University, The Orbital Technologies Corporation, Rutgers University, and Purdue University, all tasked to test the feasibility of using LEDs to advance aspects of the horticulture industry [National Institute of Food and Agriculture Specialty Crop Research Initiative (SCRI) Grant 201051181-21369, http://leds.hrt.msu.edu]. Participation in this project has given not only valuable technical perspective about specialty-crop lighting issues (Mitchell et al., 2012) but also exposure to a wide range of opinions about LEDs for plant lighting from outside academic circles. In this proceedings of an ASHS combined colloquium/workshop invited presentation, the author gives the perspective of an academic researcher and his colleagues trying to balance the objective mission of the landgrant system against the entrepreneurial spirit of the business community driven by very different goals. The author strikes a "stateof-the art" posture for LED technology status relative to commercial plant-lighting needs. One difference noted herein between the science-driven research community and business-driven industry is that applied science

Received for publication 3 Dec. 2014. Accepted for publication 15 Jan. 2015.

The assistance of Celina Gomez with manuscript critical review and reference application is gratefully acknowledged.

Sponsorship by U.S. Department of Agriculture National Institute of Food and Agriculture Specialty Crop Research Initiative grant 2010-51181-21369 provided the opportunity to make the observations communicated in this article.

${ }^{1}$ Professor.

${ }^{2}$ Corresponding author. E-mail: cmitchel@purdue. edu. and demand for commercial application are on different time scales.

\section{BUSINESS INTEREST IN LEDS FOR HORTICULTURE}

There is great interest within the business sector regarding LEDs for horticulture. Members of our SCRI project team are contacted frequently by growers wanting to know if they should buy LEDs now, if they should wait for improvements in LED technology before they buy, what should be the characteristics of LEDs they might buy, and who they should buy from if they decide to buy now. Inquiries typically come from growers who want to use LEDs to supplement sunlight in greenhouses for vegetable and herb propagation or production, as well as from entrepreneurs interested in using LEDs for indoor agriculture, urban farming, or vertical farming applications. The latter typically are interested in LEDs for sole-source lighting of quick-turning greens that do not require high light levels for production. Many entrepreneurs are thinking about LED applications for horticulture, and the global business community acutely senses LEDs as a profitable enterprise for near-future sustainable agriculture.

\section{NATURE OF INQUIRIES AND RESPONSES}

Those making private enterprise inquiries about LEDs assume that academic researchers working on LEDs for specialtycrop production have the answers to their questions, so they seek advice as if we were outreach specialists in a mature field. Quite frankly, we do not have the answers to many entrepreneurial questions. The field of LED lighting for specialty-crop propagation and production is far from mature, and much research remains to be conducted before the LED plant field becomes mature enough for dedicated academic outreach positions. However, members of our LED research team do not discourage growers or entrepreneurs from adopting early generation commercial LED technology that presently is on the market. We do not endorse or criticize specific commercial product lines. We do recommend to growers that, before they make a significant investment in LED hardware, they conduct their own research trials, at least on a small scale, comparing LED technology with established lighting technology that they already may be using.

\section{CONTRASTS BETWEEN COMMERCIAL AND ACADEMIC R \& D}

Project team researchers see LED product advertisements and testimonials on the internet, in e-mails, or endorsement claims on web sites about LED product performance that seem premature or questionable. Meanwhile, academic research plods along testing hypotheses, working systematically to turn out statistically validated, peer-reviewed publications that are incremental contributions, and training researchers who will become future experts on LED applications for horticulture. How commercial product specifications come about usually is proprietary, and sufficient technical information typically is not available for independent validation. That also is not what academic researchers typically are tasked to do. In contrast, federally funded academic research becomes public domain once it is published. Companies may advertise that they collaborate with universities testing their LED hardware, and those tests indicated how well their company's equipment worked. Intellectual property rights on both sides also are 
an obstacle for needed academic/industrial collaboration. If commercial LED equipment is being tested on campus as part of a larger, federally funded research program, there may be a conflict of interest if a commercial stakeholder donating LED equipment requests unpublished data for publicity purposes or delay of publication for marketing purposes.

\section{GENERATIONAL LED HARDWARE}

Early generation commercial LED hardware typically includes red LEDs, because broadband red $(600-700 \mathrm{~nm})$ is the most efficient waveband for driving photosynthesis (Inada, 1976; McCree, 1972). Red light also promotes fresh and dry weight gain, stem elongation, and leaf expansion of many species (Heo et al., 2002; Johkan et al., 2010; Wu et al., 2007). Because the first LED research with plants involved solesource lighting and some of the original test species grew with red light alone, red became and has remained the "staple" waveband with which to drive photosynthesis and vegetative growth (Bula et al., 1991; Goins et al., 1997). However, when it was found that plants growing adequately with red alone grew even better when a little blue light was added (Brown et al., 1995; Goins et al., 1998; Hoenecke et al., 1992; Tripathy and Brown, 1995; Yorio et al., 1998), the idea of adding blue LEDs to arrays gained momentum. Not only is the blue light peak within the second-most efficient broadband wavelength (400-500 nm) of an instantaneous quantumresponse curve (Inada, 1976; McCree, 1972) but blue light is also essential in regulating photomorphogenic plant development, including stem elongation (Brown et al., 1995; Cosgrove and Green, 1981; Dougher and Bugbee, 2001; Hoenecke et al., 1992; Kigel and Cosgrove, 1991; Nanya et al., 2012; Okamoto et al., 1997; Shinkle and Jones, 1988), leaf expansion (Cope and Bugbee, 2013; Dougher and Bugbee, 2001; Johkan et al., 2010; Li and Kubota, 2009), and perhaps flowering (Giliberto et al., 2005; Nanya et al., 2012). Of course, blue light also is important for phototropism and photonastic responses, including stomatal movements (Blaauw and Blaauw-Jansen, 1970; Folta and Spalding, 2001; Kagawa et al., 2001; Kinoshita et al., 2001; Zeiger, 2010). Blue light, then, is a logical addition to LED arrays for plant growth and development, especially in solesource lighting applications. But, how much blue? Mid-day solar light is about one-third broadband blue (Gómez and Mitchell, 2015) and may be at an intensity during certain seasons that early generation LED arrays cannot duplicate. However, if leafy greens such as lettuce are grown under low-intensity sole-source LED lighting, only $5 \%$ of total photosynthetic photon flux is needed as blue (Hoenecke et al., 1992; Poulet et al., 2014). More blue than that progressively inhibits stem elongation and leaf expansion (Cope and Bugbee, 2013; Dougher and Bugbee, 2001; Hoenecke et al., 1992). So, why would it even be considered to supplement greenhouse sunlight with blue LED light, especially since the sky is blue for most of the day, anyway? It appears that multiple environmental interactions determine plant sensitivity and response to supplemental greenhouse lighting in general, and to blue light in particular (Gómez and Mitchell, 2015; Trouwborst et al., 2010). Because climate and weather differ regionally and seasonally, plant responses to blue light may vary regionally and seasonally as well. Early generation LED hardware was not designed to accommodate or adapt to highly complex interactions among light intensity, daily light integral (DLI), spectral composition, and changing species and cultivar sensitivities.

\section{(RE)-DISCOVERING THE SOLAR SPECTRUM}

Plants evolved under broadband solar light that shifts both in intensity as well as in spectral distribution throughout the day, and in duration seasonally. Thus, growing plants under red light alone and then discovering that adding a little blue light makes them grow even better is not particularly surprising. We are gradually rediscovering the value of white light for growing plants, at least the white that the sun contains. Throw in a little green light along with red and blue, and plant species with some mutual leaf shading grow even better (Kim et al., 2004; Lu et al., 2012). Then add some far red light and plants grow taller (Brown et al., 1995; Chia and Kubota, 2010); and some photoperiodic classes of plants flower better when far red light is present during night-break lighting (Deitzer et al., 1979; Downs, 1956; Kohyama et al., 2014). Some species develop physiological disorders (e.g., gall-like tumors on their leaves and shoot tips) under narrow spectrum and/or dim light (Massa et al., 2006; Morrow and Wheeler, 1997). The presence of far red light can prevent such disorders in some species (Rangarajan and Tibbitts, 1994), but intumescence growth generally is thought to be due to a deficiency of ultraviolet radiation (Morrow and Tibbitts, 1988). Ultraviolet also promotes biosynthesis of pigments and accumulation of a wide array of phytochemicals in fruits and vegetables ( $\mathrm{Li}$ and Kubota, 2009; Samuoliene et al., 2013). So, will we eventually need to reassemble the complete solar spectrum in growth chambers and warehouses for maximum specialty-crop yield and quality? Are white LEDs per se the answer? Present white LED technology consists of blue LEDs with a phosphor coating inside the lens cap (Pimputkar et al., 2009), but the white emissions still are rich in blue light, so they may not have exactly the same effect as solar white light. Plants growing in a lowintensity, sole-source lighting scenario may be much more sensitive to blue light than they are outdoors or in a greenhouse. There are phosphors for cool-white, neutral-white, and warm-white hues, among others, but broadband white LEDs are significantly less efficient than monochromatic LED colors that, when blended together, generate white light (Bourget, 2008; Mills, 2004).

\section{CHALLENGES TO PRESCRIBING SPECIFIC PLANT GROWTH SPECTRA}

By discovering and eliminating photomorphological abnormalities or physiological disorders caused by certain spectral deficiencies or imbalances, and by optimizing desired plant responses to spectrum, photon flux, and duration, we should be able to systematically assemble functional LED light recipes that work for specific crops. But even in sole-source LED lighting scenarios, researchers encounter unexpected plant responses. In a dose-response curve for stem elongation of cucumber between $100 \%$ red light and $100 \%$ blue light, for example, increasing proportions of blue light at constant total light intensity incrementally inhibited stem elongation compared with the red control, until it came to $100 \%$ blue light, under which stem length became significantly longer than that of the red control (Hernández and Kubota, 2014a). Such anomalous plant responses are not presently predictable. When the interactions between photoreceptors, unknown environmental factors, and physiological response systems are worked out, then it no longer will be a mystery, but for now such observations reduce our ability to accurately predict outcomes and make unambiguous generalizations, even for sole-source lighting. There is no substitute for the systematic doseresponse curve with multiple wavebands and light levels. This will be easier to do in a highly controlled environment than for supplemental lighting in a semicontrolled greenhouse environment, but it still is important to establish dose responses in the greenhouse. Not only are there seasonally changing plant sensitivities to supplemental lighting spectra in the presence of a changing solar background (Gómez and Mitchell, 2015) but also there appear to be species and cultivar differences as well (Gunnlaugsson and Adalsteinsson, 2006; Hernández and Kubota, 2014b; Hogewoning et al., 2012). There also may be differences in spectral sensitivity at different stages of a cropping cycle (Cope and Bugbee, 2013). So, must growers be equipped with all-purpose LED arrays containing red, blue, perhaps green or white, and even far red LEDs, all of which are independently adjustable in intensity? Should future LED arrays include ultraviolet light? Do growers need controlled environment chambers in which to mimic conditions that different species and cultivars will encounter in the greenhouse at different times of year? Most likely, growers will not pursue such levels of sophistication or expense in commercial trials. Academics working in collaboration with the lighting industry will have to establish such databases. 


\section{RESEARCH-GRADE LED ARRAY REQUIREMENTS}

Certainly, research-grade LED arrays need multiple wavebands that can be independently varied in intensity of output so that different hues and color ratios can be obtained, including variable red : blue ratios, red: far red ratios, and others, depending on the desired plant response. Such arrays typically need to be densely populated with high-output LEDs to achieve both target photon fluxes/ DLIs as well as spectral blending during closecanopy lighting, so they also need to be actively heat sinked, typically by forced-air cooling (Comerford, 2011; Keeping, 2011). However, for very high-output LED arrays, refrigerated, recirculating water may be needed (C.M. Bourget, personal communication).

\section{COMMERCIAL CONSIDERATIONS FOR LED ARRAYS}

If multiple wavebands are needed for normal photomorphogenic development of a given crop, overhead arrays must be packed densely with different colors of LEDs, especially if moderate-to-high light intensity is required. This is not a problem for solesource lighting applications, where there is no need to worry about LED arrays blocking sunlight, but it could be an issue for supplemental lighting in a greenhouse, especially if the grower wants to use as much sunlight as possible to save on supplemental lighting costs.

Because waste heat from LEDs is rejected remote from photon-emitting surfaces, LEDs can be placed close to plant surfaces for energy savings (Bourget, 2008). For multicolor arrays, the minimum distance between an LED array and the crop surface will be dictated by uniformity of color blending within the light beam rather than by tissuescorching considerations, as it is for highintensity discharge lighting. If the goal is uniform lighting of dense populations of seedlings or cuttings for propagation purposes, why use a greenhouse or sunlight at all if you want to use LEDs for photomorphogenic manipulation of future transplants? Arrays would have to be populated so densely with LEDs to get uniform, sufficient light intensity at plant level that most sunlight in a greenhouse would be blocked by the array fixture, anyway. One important question to answer if this approach to propagation is considered: How well will seedling or graft transplants produced under sole-source, narrow-spectrum LED lighting adapt to subsequent transplantation to the greenhouse or field, where transplants then will encounter broadband solar light?

\section{DISTRIBUTION OF SOLAR AND SUPPLEMENTAL LIGHTING IN THE GREENHOUSE}

Distribution of all sources of lighting also is an important consideration for the greenhouse, especially for crop production, where blockage of sunlight by LED arrays needs to be minimized. For overhead supplemental lighting, widely spaced, narrow, parallel bars of LEDs perpendicular to the track of the sun across the greenhouse might be the way to go but may not yield very high supplemental light intensities due to low population densities of LEDs along the bars and wide spacing of the bars. For high-wire crops, placement of LEDs along the side or within the foliar canopy compensates for mutual shading of lower leaves by upper leaves to overhead light (Deram et al., 2014; Dueck et al., 2012; Gómez et al., 2013; Gómez and Mitchell, 2014; Jokinen et al., 2012; Lu et al., 2012; Trouwborst et al., 2010). While some commercial LED arrays are actively heat sinked, others are only passively heat sinked, requiring conductive heat transfer between the fixtures and surrounding air. This limits the population density of LEDs that can be accommodated and the intensity of light that can be emitted from an array. Otherwise, the LEDs would become so hot that their performance and lifetime would be severely compromised (Bourget, 2008). The operational life of fans used for active heat sinking also likely is significantly less than that of the LEDs themselves, further limiting the operational lifespan of commercial LED products. Active heat sinking does permit placement of LEDs for close-canopy or intracanopy lighting without overheating plant tissues or damaging LEDs (Gómez et al., 2013; Massa et al., 2005a, 2005b; Morrow, 2008; Poulet et al., 2014).

\section{EARLY GENERATION COMMERCIAL LED ARRAYS VERSUS FLEXIBLE RESEARCH ARRAYS}

Because the initial capital investment of converting from traditional lighting technology to LED lighting technology already is high (Nelson and Bugbee, 2014), early generation commercial LED arrays tend to have limited spectral choices, fixed-color ratios, modest output intensities, passive heat sinking, and/or limited light distribution geometry for certain lighting applications. Thus, they are somewhat limited in their capability for determining optimum light recipes for certain kinds of crops. But, those are the capabilities that manufacturers and vendors feel are marketable, now, before systematic academic research confirms, extends, or fine tunes industrial research findings. Because one-of-a-kind, research quality LED arrays have added features and more lighting capabilities than commercial prototypes (e.g., multispectral, individually adjustable, high output), academic researchers are in a better position to fine-tune light recipes. Whether more sophisticated LED technology is needed for commercial application depends on the lighting application. If it is just to increase DLI, then it may not matter whether the red : blue ratio or electrical efficiency is optimized in order for an LED product to be effective. But, if the goal is to make sure that hypocotyls elongate sufficiently for seedlings to be used as rootstocks for grafted transplant production (Chia and Kubota, 2010), for certain cultivars to flower on a specific schedule (Craig and Runkle, 2013; Kohyama et al., 2014), or to not inhibit leaf expansion of a leafy-green crop (Cope and Bugbee, 2013; Dougher and Bugbee, 2001; Hoenecke et al., 1992), then precise spectral mixes may be very important. Research with flexible LED technology ultimately will determine what LED hardware requirements must be.

\section{ANTICIPATED TRENDS IN LED TECHNOLOGY}

Industrial research using early generation commercial LED hardware can generate light recipes, but if those recipes are limited by early generation LED technology on the market, then the lighting protocols generated will fall within those limits as well. As LED efficiencies continue to climb over time (Haitz and Tsao, 2011) and as costs of massproducing new LED technology come down, growers who use future LED products will benefit even more from ongoing academic research than present growers do from past LED research. Manufacturers, vendors, and growers currently are benefitting from public sector LED research that began $>20$ years ago (Barta et al., 1992; Bula et al., 1991; Morrow et al., 1989). Products spinning out from present-day research will benefit industry, growers, and consumers much faster since LED applications research is rising rapidly. There appears to be a large market for purveyors of quality LED technology for horticultural applications. Who will do the needed research to empower that industry fully? Where will the needed resources to do so properly come from? And what role will open collaboration play?

\section{Literature Cited}

Barta, D.J., T.W. Tibbitts, R.J. Bula, and R.C. Morrow. 1992. Evaluation of light emitting diode characteristics for a space-based plant irradiation source. Adv. Space Res. 12:141-149.

Blaauw, O. and G. Blaauw-Jansen. 1970. The phototropic responses of Avena coleoptiles. Acta Bot. Neerl. 19:755-763.

Bourget, C.M. 2008. An introduction to lightemitting diodes. HortScience 43:1944-1946.

Brown, C.S., A.C. Schuerger, and J.C. Sager. 1995. Growth and photomorphogenesis of pepper plants under red light-emitting diodes with supplemental blue or far-red lighting. J. Amer. Soc. Hort. Sci. 120:808-813.

Bula, R.J., R.C. Morrow, T.W. Tibbitts, D.J. Barta, R.W. Ignatius, and T.S. Martin. 1991. Lightemitting diodes as a radiation source for plants. HortScience 26:203-205.

Chia, P.L. and C. Kubota. 2010. End-of-day far-red light quality and dose requirements for tomato rootstock hypocotyl elongation. HortScience 45:1501-1506.

Comerford, R. 2011. Controlling LED Junction Temperature in Lighting Applications. <http://www. digikey.com/us/en/techzone/lighting/resources/ articles/controlling-led-junction-temperature.html>.

Cope, K.R. and B. Bugbee. 2013. Spectral effects of three types of white light-emitting diodes on plant growth and development: Absolute versus relative amounts of blue light. HortScience 48:504-509. 
Cosgrove, D.J. and P.B. Green. 1981. Rapid suppression of growth by blue light. Plant Physiol. 68:1447-1453.

Craig, D.S. and E.S. Runkle. 2013. A moderate to high red to far-red light ratio from light-emitting diodes controls flowering of short-day plants. J. Amer. Soc. Hort. Sci. 138:167-172.

Deitzer, G.F., R. Hayes, and M. Jabben. 1979. Kinetics and time dependence of the effect of far red light on the photoperiodic induction of flowering in Wintex barley. Plant Physiol. 64:1015-1021.

Deram, P., M.G. Lefsrud, and V. Orsat. 2014. Supplemental lighting orientation and red-toblue ratio of light-emitting diodes for greenhouse tomato production. HortScience 49:448-452.

Dougher, T.A.O. and B. Bugbee. 2001. Differences in the response of wheat, soybean, and lettuce to reduced blue radiation. Photochem. Photobiol. 73:199-207.

Dueck, T.A., J. Janse, B.A. Eveleens, F.L.K. Kempkes, and L.F.M. Marcelis. 2012. Growth of tomatoes under hybrid LED and HPS lighting systems. Acta Hort. 952:335-342.

Downs, R.J. 1956. Photoreversibility of flower initiation. Plant Physiol. 31:279-284.

Folta, K.M. and E.P. Spalding. 2001. Unexpected roles for cryptochrome 2 and phototropin revealed by high-resolution analysis of blue light-mediated hypocotyl growth inhibition. Plant J. 26:471-478.

Giliberto, L., G. Perrotta, P. Pallara, J.L. Weller, P.D. Fraser, P.M. Bramley, A. Fiore, M. Tavazza, and G. Giuliano. 2005. Manipulation of the blue light photoreceptor cryptochrome 2 in tomato affects vegetative development, flowering time, and fruit antioxidant content. Plant Physiol. 137:199-208.

Goins, G.D., N.C. Yorio, M.M. Sanwo, and C.S. Brown. 1997. Photomorphogenesis, photosynthesis, and seed yield of wheat plants grown under red light-emitting diodes (LEDs) with and without supplemental blue lighting. J. Expt. Bot. 48:1407-1413.

Goins, G.D., N.C. Yorio, M.M. Sanwo-Lewandowski, and C.S. Brown. 1998. Life cycle experiments with Arabidopsis under red light-emitting diodes (LEDs). Life Support Biosph. Sci. 5:143-149.

Gómez, C. and C.A. Mitchell. 2014. Supplemental lighting for greenhouse-grown tomatoes: Intracanopy LED towers vs. overhead HPS lamps. Acta Hort. 1037:855-862.

Gómez, C. and C.A. Mitchell. 2015. Growth responses of tomato seedlings to different spectra of supplemental lighting. HortScience 50:1-7.

Gómez, C., R.C. Morrow, C.M. Bourget, G.D Massa, and C.A. Mitchell. 2013. Comparison of intracanopy light-emitting diode towers and overhead high-pressure sodium lamps for supplemental lighting of greenhouse-grown tomatoes. HortTechnology 23:93-98.

Gunnlaugsson, B. and S. Adalsteinsson. 2006. Interlight and plant density in year-round production of tomato at northern latitudes. Acta Hort. 711:71-75.

Haitz, R. and J.Y. Tsao. 2011. Solid-state lighting: 'The case' 10 years after and future prospects. Phys. Status Solidi 208:17-29.

Heo, J., C. Lee, D. Chakrabarty, and K. Paek. 2002. Growth responses of marigold and salvia bedding plants as affected by monochromic or mixture radiation provided by a light emitting diode (LED). Plant Growth Regulat. 38:225-230.

Hernández, R. and C. Kubota. 2014a. Blue light dose-response of growth and morphology of cucumber seedlings under different blue and red photon flux ratios using LEDs. HortScience 49:S238-S239.
Hernández, R. and C. Kubota. 2014b. LEDs supplemental lighting for vegetable transplant production: Spectral evaluation and comparisons with HID technology. Acta Hort. 1037:829-836.

Hoenecke, M.E., R.J. Bula, and T.W. Tibbitts. 1992. Importance of 'blue' photon levels for lettuce seedlings grown under red-lightemitting diodes. HortScience 27:427-430.

Hogewoning, S.W., G. Trouwborst, E. Meinen, and W. van leperen. 2012. Finding the optimal growth-light spectrum for greenhouse crops. Acta Hort. 956:357-363.

Johkan, M., K. Shoji, F. Goto, S. Hashida, and T. Yoshihara. 2010. Blue light-emitting diode light irradiation of seedlings improves seedling quality and growth after transplanting in red leaf lettuce. HortScience 45:1809-1814.

Jokinen, K., L.E. Särkkä, and J. Näkkilä. 2012. Improving sweet pepper productivity by LED interlighting. Acta Hort. 956:59-66.

Kagawa, T., T. Sakai, N. Suetsugu, K. Oikawa, S. Ishiguro, T. Kato, S. Tabata, K. Okada, and M. Wada. 2001. Arabidopsis NPL1: A phototropin homolog controlling the chloroplast highlight avoidance response. Science 291:2138-2141.

Keeping, S. 2011. Calculating LED Junction Temperature in Lighting Applications. $<\mathrm{http} / / /$ www.digikey.com/us/en/techzone/lighting/ resources/articles/calculating-led-junctiontemperature.htmls>.

Kigel, J. and D.J. Cosgrove. 1991. Photoinhibition of stem elongation by blue and red light: Effects and cell wall properties. Plant Physiol. 95:1049-1056.

Kim, S.-J., E.-J. Hahn, J.-W. Heo, and K.-Y. Paek. 2004. Effects of LEDs on net photosynthetic rate, growth, and leaf stomata of chrysanthemum plantlets in vitro. Sci. Hort. 101:143-151.

Kinoshita, T., M. Doi, N. Suetsugu, T. Kagawa, M. Wada, and K. Shimazaki. 2001. Phot1 and phot 2 mediate blue light regulation of stomatal opening. Nature 414:656-660.

Kohyama, F., C. Whitman, and E.S. Runkle. 2014. Comparing flowering responses of long-day plants under incandescent and two commercial light-emitting diode lamps. HortTechnology 24:490-495

Inada, K. 1976. Action spectra for photosynthesis in higher plants. Plant Cell Physiol. 17:355-365.

Li, Q. and C. Kubota. 2009. Effects of supplemental light quality on growth and phytochemicals of baby leaf lettuce. Environ. Expt. Bot. 67:59-64.

Lu, N., T. Maruo, M. Johkan, M. Hohjo, S Tsukagoshi, Y. Ito, T. Ichimura, and Y. Shinohara. 2012. Effects of supplemental lighting with light-emitting diodes (LEDs) on tomato yield and quality of single-truss tomato plants grown at high planting density. Envrion. Control Biol. 50:63-74.

Massa, G.D., J.C. Emmerich, M.E. Mick, R.J. Kennedy, R.C. Morrow, and C.A. Mitchell. 2005a. Development and testing of an efficient LED intracanopy lighting design for minimizing equivalent system mass in an advanced lifesupport system. Gravit. Space Biol. Bull. 18:87-88.

Massa, G.D., J.C. Emmerich, R.C. Morrow, and C.A. Mitchell. 2005b. Development of a reconfigurable LED plant-growth lighting system for equivalent system mass reduction in an ALS. SAE Technical Paper 2005-01-2955.

Massa, G.D., J.C. Emmerich, R.C. Morrow, C.M. Bourget, and C.A. Mitchell. 2006. Plantgrowth lighting for space life support: A review. Gravit. Space. Biol. 19:19-29.

McCree, K.J. 1972. The action spectrum absorptance and quantum yield of photosynthesis in crop plants. Agr. Meteorol. 9:191-216.
Mills, A. 2004. Lighting: The progress \& promise of LEDs. III-Vs Review 17:39-41.

Mitchell, C., A.J. Both, C.M. Bourget, J.F. Burr, C. Kubota, R.G. Lopez, R.C. Morrow, and E.S. Runkle. 2012. LEDs: The future of greenhouse lighting! Chron. Hort. 52(1):6-12.

Morrow, R.C. 2008. LED Lighting in Horticulture. HortScience 43:1947-1950.

Morrow, R.C. and T.W. Tibbitts. 1988. Evidence for involvement of phytochrome in tumor development on plants. Plant Physiol. 88:1110-1114.

Morrow, R.C. and R.M. Wheeler. 1997. Physiological disorders, p. 133-141. In: R.W Langhans and T.W. Tibbitts (eds.). A Growth Chamber Manual, 2nd ed. Iowa State Univ. Press. North Central Regional Research Publication.

Morrow, R.C., R.J. Bula, and T.W. Tibbitts. 1989. Light emitting diodes as a photosynthetic irradiance source for plants. ASGSB Bul. 3:60.

Nanya, K., Y. Ishigami, S. Hikosaka, and E. Goto. 2012. Effects of blue and red light on stem elongation and flowering of tomato seedlings. Acta Hort. 956:264-266.

Nelson, J.A. and B. Bugbee. 2014. Economic analysis of greenhouse lighting: Light emitting diodes vs. high intensity discharge fixtures. PLoS One 9:1-10.

Okamoto, K., T. Yanagi, and S. Kondo. 1997. Growth and morphogenesis of lettuce seedlings raised under different combinations of red and blue light. Acta Hort. 445:149-157.

Pimputkar, S., J.S. Speck, S.P. DenBaars, and S. Nakamura. 2009. Prospects for LED lighting. Nat. Photonics 3:180-182.

Poulet, L., G.D. Massa, R.C. Morrow, C.M. Bourget, R.M. Wheeler, and C.A. Mitchell. 2014. Significant reduction in energy for plant-growth lighting in space using targeted LED lighting and spectral manipulation. Life Sci. Space Res. 2:43-53.

Rangarajan, A. and T.W. Tibbitts. 1994. Exposure with far-red radiation for control of oedema injury on 'Yale' ivy geranium. HortScience 29:38-40

Samuoliene, G., A. Brazaityte, R. Sirtautas, A. Virsile, J. Sakalauskaite, S. Sakalauskiene, and P. Duchovskis. 2013. LED illumination affects bioactive compounds in Romaine baby leaf lettuce. J. Sci. Food Agr. 93:3286-3291.

Shinkle, J.R. and R.L. Jones. 1988. Inhibition of stem elongation in Cucumis seedlings by blue light requires calcium. Plant Physiol. 86:960966.

Tripathy, B.C. and C.S. Brown. 1995. Root-shoot interaction in the greening of wheat seedlings grown under red light. Plant Physiol. 107:407-411.

Trouwborst, G., J. Oosterkamp, S.W. Hogewoning, J. Harbinson, and W. van Ieperen. 2010. The responses of light interception, photosynthesis and fruit yield of cucumber to LED-lighting within the canopy. Physiol. Plant. 138:289-300.

Wu, M.C., C.Y. Hou, C.M. Jiang, Y.T. Wang, C.Y. Wang, H.H. Chen, and H.M. Chang. 2007. A novel approach of LED light radiation improves the antioxidant activity of pea seedlings. Food Chem. 101:1753-1758.

Yorio, N.C., R.M. Wheeler, G.D. Goins, M.M. Sanwo-Lewandowski, C.L. Mackowiak, C.S. Brown, J.C. Sager, and G.W. Stutte. 1998. Blue light requirements for crop plants used in bioregenerative life support systems. Life Support Biosph. Sci. 5:119-128.

Zeiger, E. 2010. Blue light responses: Morphogenesis and stomatal movements, p. 521-543. In L. Taiz and E. Zeiger (eds.). Plant Physiology. 5th ed. Sinauer Associates, Inc., Sunderland, MA. 